\title{
Commentary on suicide and homelessness: What differentiates homeless persons who died by suicide from other suicides in Australia? A comparative analysis using a unique mortality registry
}

\author{
Richard C. Christensen
}

Received: 24 October 2013/ Accepted: 28 October 2013/Published online: 9 November 2013

(C) Springer-Verlag Berlin Heidelberg 2013

Several years ago I published an essay lamenting the lack of research addressing the issue of suicide within the homeless population [1]. As an academic community psychiatrist in the United States (US) I have spent over 25 years providing clinical care to homeless persons who are experiencing the effects of mental illness and/or substance use disorders. What prompted my plea for more research was the suicide of a young adult male patient who was under my care for schizophrenia and polysubstance abuse. His name was Thomas. He had spent much of his adult life on the streets and in shelters. He was in his late 20s when he suicided, just a day after I had seen him in my clinic. Incredulously, prior to taking his own life he had appeared to be doing very well from the rough clinical and social measures we use in this imprecise practice of medicine and rehabilitation. His suicide forced me to ask those painful questions every clinician performs through a selfadministered cross-examination following such a tragic event: what forces conspired that to led to this final act of self-destruction? What risk factors went undetected? What did I miss? What could I have done better? My search of the literature provided a wealth of information on suicide among patients with psychiatric illness, as well as comorbid substance use disorders, but I found precious little on the impact homelessness might have upon the risk of suicide. The piece published in this issue of Social Psychiatry and Psychiatric Epidemiology, entitled, "What differentiates homeless persons who died by suicide from other suicides in Australia? A comparative analysis using a unique mortality registry", is a tremendous first step in

R. C. Christensen $(\bowtie)$

Department of Psychiatry, University of Florida College of

Medicine, Gainesville, USA

e-mail: rchris@ufl.edu bridging a long-neglected gap in the body of health care research for persons experiencing homelessness [2].

This study by Arnautovska, Sveticic and De Leo is an interesting, timely and well-written endeavor to identify the most prominent demographic and clinical characteristics of homeless people who died by suicide in Queensland, Australia, over a 20-year period (1990-2009). Utilizing a mortality dataset derived from the Queensland Suicide Registry, the investigators determined that homeless persons had a suicide rate that was nearly twice higher than their non-homeless counterparts. The risk profile that emerged among this cohort of homeless persons was one that identified gender as significant (males completed more suicides than females), being of young age, unemployed, being single or never married, and having at least one physical illness. Not surprisingly, substance use disorders and untreated mental illness were prominent characteristics among those who took their own lives.

In the US, on any given night, there are nearly 650,000 individuals who live in shelters, on the streets, in abandoned buildings, or move from one unstable residence to another as "couch surfers" [3]. Nearly 25-28\% have a serious mental illness and it has been estimated that $50 \%$ suffer from a substance use disorder [4]. In the large Florida city within which I practice, $70 \%$ of the population of homeless persons is male, unmarried, and have an average age of 40 years. $90 \%$ of our local homeless population report being unemployed [5]. Like so many others in this country who live in extreme poverty, persons who are homeless have little access to formal primary and mental health services since they lack employer-based or public health care insurance. Hence, when I reflect upon the implications of this study in my own clinical practice I recognize that nearly all my patients are at increased risk for suicide compared to their counterparts in the general 
population. Does that surprise me? Not really, but it does motivate me to advocate for change and take action with regard to implementing suicide prevention strategies targeting this high-risk population.

This study has clear, meaningful and practical implications for those who work directly with persons who are homeless: hospital social workers, shelter providers, case managers, primary care physicians, emergency department nurses, mental health counselors and psychiatrists. The "demographic and clinical characteristics" identified in this study can, and should, serve as "red flags" for any provider of care to those who are experiencing homelessness. On one hand, simple, brief suicide prevention screening tools can be developed that take into account the risk factors underscored in this study. As a formal suicide prevention initiative, administration can be required for every admission to a homeless shelter, before discharging an unsheltered person from a hospital medical unit, and with every intake at a safety-net clinic that treats homeless individuals. Certainly one can advocate for this approach at each encounter for those seeking/receiving mental health or substance use services. On the other hand, even without the use of a formal tool, an awareness of the aforementioned risk factors should prompt all service providers to ask a very few, simple questions put to the person before them who is homeless:

Are you feeling hopeless about the present or future?

Have you had thoughts about taking your life?

When did you have these thoughts and do you have a plan to take your life?
The authors of this study have provided a valuable and desperately needed insight into the characteristics of homeless persons who may be most at risk for ending their lives. The findings of their work, if applied and shaped into suicide prevention measures specifically adapted to meet the unique needs of persons experiencing homelessness, can truly be life saving. I remain grateful for their contribution to the field of preventive health care for homeless persons because I never again want to lose another Thomas.

\section{References}

1. Christensen RC, Garces LK (2006) Where is the research on homeless persons and suicide? Psychiatr Serv 57(4):447

2. Arnautovska U, Sveticic J, De Leo D (2013) What differentiates homeless persons who died by suicide from other suicides in Australia? A comparative analysis using a unique mortality register. Soc Psychiatry Psychiatr Epidemiol. doi:10.1007/s00127-0130774-z

3. The 2009 Homeless Assessment Report to Congress. Available at http://www.hudhre.info/documents/5thHomelessAssessmentReport. pdf. Accessed October 16, 2013

4. The United States Conference of Mayors. Hunger and homelessness in America's cities, a 25 city survey. Washington, DC. Conference of Mayors, 2008 Dec. Available at: http://usmayors. org/pressrelaeases/documents/hungerhomelessnessreport_121208. pdf. Accessed October 162013

5. 2012 Report on the Homeless Populations in Duval, Clay and Nassau Counties (Florida, USA). Emergency Services and Homeless Coalition of Jacksonville, Florida and Northeast Florida Center of Community Initiatives Available at: http://www.unf. edu/.../aa/coas/cci/projects/2012\%20Homeless\%20Report.pdf. Accessed October 162013 